\title{
Iron deficiency in early childhood
}

\author{
Patricia C. Parkin MD, Jonathon L. Maguire MD MSc
}

An 18-month-old girl is seen by her family physician for her 18-month check-up. Her weight and height are at the 50th percentile. She was breastfed in the first year, introduced to complementary (i.e., solid) foods at 6 months and cow's milk at 12 months, and currently drinks $1 \mathrm{~L}$ of cow's milk per day by bottle. Her parents describe her as a fussy infant who has never eaten solid foods well and has poor meat and vegetable intake. They ask if she should take a vitamin and mineral supplement.

\section{Is the child at risk for iron deficiency?}

As a healthy term infant, this child was born with sufficient iron stores for the first 4 to 6 months. However, at her age, she is at risk for iron deficiency, which peaks in prevalence during the toddler years (1-3 yr). ${ }^{1}$ Although there are no nationally representative data, small regional studies suggest a prevalence among young Canadian children of $12 \%$ or higher for nonanemic iron deficiency and $1.5 \%$ or higher for iron deficiency anemia. ${ }^{2}$ In addition, she has several dietary risk factors (Box 1), including prolonged bottle use, excessive consumption of cow's milk and poor intake of iron-rich complementary foods. ${ }^{1,3-5}$ Should this child have iron deficiency, she would be at risk for poor cognitive development, which has been shown in animal studies, observational studies and randomized trials. ${ }^{67}$

The role of screening and prevention for iron deficiency remains unclear. In a consensus statement, the American Academy of Pediatrics recommends the following: that universal screening be employed to identify anemia at 12 months of age using risk assessment and laboratory tests, that exclusively and partially breastfed infants receive $1 \mathrm{mg}$ elemental iron/kg daily beginning at 4 months of age until iron-containing complementary foods are introduced, and that preterm breastfed infants receive $2 \mathrm{mg}$ elemental iron $/ \mathrm{kg}$ daily by 1 month of age until weaned to ironfortified formula or beginning complementary foods. ${ }^{1}$ There is no Canadian recommendation for routine screening or iron supplementation. ${ }^{8}$

\section{What investigations, if any, should be ordered?}

On clinical examination, this child does not have pallor. However, in a meta-analysis, the diagnostic accuracy of pallor (i.e., conjunctival, palmar or nail bed) was shown to be poor until anemia is severe (i.e., hemoglobin level $<50 \mathrm{~g} / \mathrm{L}$ ). ${ }^{9}$ Considering this child's age and risk factors, laboratory testing, including hemoglobin, serum ferritin and C-reactive protein levels, is indicated. ${ }^{1}$ Based on the results (hemoglobin $87 \mathrm{~g} / \mathrm{L}$, serum ferritin $6 \mu \mathrm{g} / \mathrm{L}$ and C-reactive protein $<8.0 \mathrm{mg} / \mathrm{L}$ ), the child has iron-deficiency anemia. In children aged $1-3$ years, iron deficiency anemia is defined as a hemoglobin level of less than $110 \mathrm{~g} / \mathrm{L}$ along with a measure of iron deficiency, such as a serum ferritin level of less than $14 \mu \mathrm{g} / \mathrm{L}$, whereas nonanemic iron deficiency is defined as iron deficiency with a hemoglobin level of $110 \mathrm{~g} / \mathrm{L}$ or higher. ${ }^{10}$ The American Academy of Pediatrics recommends simultaneously measuring Creactive protein. ${ }^{1}$ If the $\mathrm{C}$-reactive protein level is elevated $(>8.0 \mathrm{mg} / \mathrm{L})$, the serum ferritin level (an acute phase reactant) may be falsely elevated, and thus the laboratory results should be interpreted with caution. ${ }^{1}$ Reticulocyte hemoglobin and transferrin receptor 1 are promising new tests of iron status. ${ }^{1}$

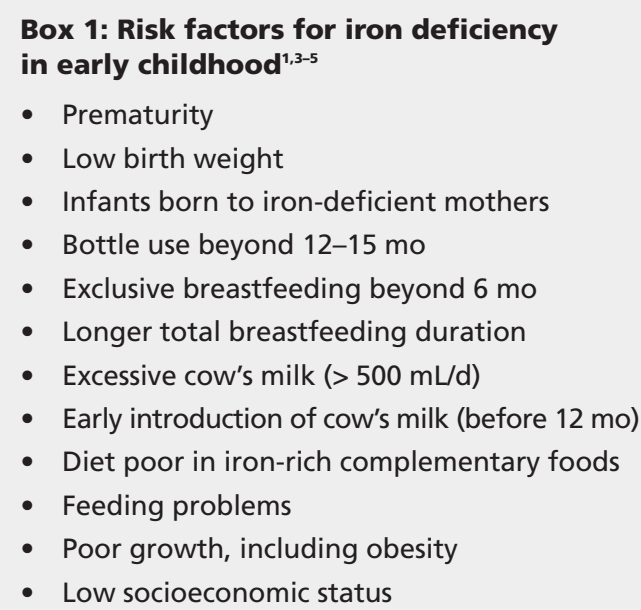

- Low socioeconomic status

Competing interests: None declared.

This article has been peer reviewed.

Correspondence to: Patricia C. Parkin, patricia.parkin@sickkids.ca

CMAJ 2013. DOI:10.1503 /cmaj.130150 
What treatment should the child receive? A Cochrane systematic review identified 2 randomized placebo-controlled trials of 2 and 4 months duration suggesting improved psychomotor development following iron therapy. The American Academy of Pediatrics report recommends that children with iron deficiency anemia be given $6 \mathrm{mg} / \mathrm{kg} / \mathrm{d}$ elemental iron (ferrous fumarate or sulfate), orally as a single dose or divided into 2 or 3 doses, for 4 months. ${ }^{1}$ Additionally, the child's parents should receive dietary advice regarding foods that are rich in iron and contain vitamin $\mathrm{C}$, and diet practices that prevent iron deficiency (Box 2). ${ }^{1,3-5}$ For children with nonanemic iron deficiency, dietary advice is recommended; ${ }^{1}$ it is not known whether the addition of oral iron is superior to dietary advice alone.

\section{What follow-up is needed?}

This child may experience difficulties with adherence because of the poor palatability of oral iron and should be monitored closely. To confirm the diagnosis and ensure adherence, she should have a repeat measurement of hemoglobin and serum ferritin 4 months after treatment is started or earlier if there are concerns about adherence.? She should undergo developmental screening and be referred for developmental assessment if there is evidence of delay.

\section{Case resolution}

The child's parents received dietary advice, and she was given oral iron for 4 months. No concerns were identified on developmental screening. Her

Box 2: Dietary advice for children aged 12 to 36 months to prevent or treat* iron deficiency ${ }^{1,3-5}$

\section{Foods rich in iron}

- High: meat and eggs

- Medium: meat alternatives (e.g., beans, tofu)

- Lower: grain products (e.g., oatmeal, enriched pasta, enriched rice), vegetables and fruit (e.g., broccoli, spinach, prune juice)

Foods containing vitamin $\mathbf{C}$ that increase iron absorption

- Fruits: citrus fruits (e.g., oranges, grapefruit) and juices, tomatoes, cantaloupe, kiwi

- Vegetables: leafy greens (e.g., spinach, cabbage), cauliflower, broccoli, Brussels sprouts, green and red peppers

Dietary practices that prevent iron deficiency

- Limit cow's milk to 2 to 3 cups $(500-750 \mathrm{~mL})$ per day

- Limit juice to $1 / 2$ to $3 / 4$ cup (125-175 mL) per day

- Cow's milk, juice and water should be offered from an open cup, and baby bottles should be discontinued when the child is $12-15$ months of age or preferably earlier

- Ensure iron-rich and vitamin C-containing foods for infants breastfed beyond 6 months

- Do not give tea, which impairs iron absorption

*Iron deficiency anemia should be treated with oral iron plus dietary advice. parents reported good adherence, improved diet and dietary practices, and improvement in her fussy behaviour. At 4 months after initiation of iron, repeat blood tests showed a hemoglobin level of $112 \mathrm{~g} / \mathrm{L}$ and serum ferritin level of $32 \mu \mathrm{g} / \mathrm{L}$. Iron was discontinued. She remained adherent to the dietary recommendations and showed appropriate growth and development. No further blood tests were ordered.

\section{References}

1. Baker RD, Greer FR. Committee on Nutrition American Academy of Pediatrics. Diagnosis and prevention of iron deficiency and iron-deficiency anemia in infants and young children (0-3 years of age). Pediatrics 2010;126:1040-50.

2. Hartfield D. Iron deficiency is a public health problem in Canada infants and children. Paediatr Child Health (Oxford) 2010;15: 347-50.

3. Sutcliffe TL, Khambalia A, Westergard S, et al. Iron depletion is associated with daytime bottle feeding in the second and third years of life. Arch Pediatr Adolesc Med 2006;160:1114-20.

4. Maguire JL, Lebovic G, Kandasamy S, et al.; the TARGet Kids! Collaboration. The relationship between cow's milk and stores of vitamin D and iron in early childhood. Pediatrics 2013;131: e144-51

5. Maguire JL, Salehi L, Birken CS, et al.; the TARGet Kids! collaboration. Association between total duration of breastfeeding and iron deficiency. Pediatrics 2013;131:e1530-7.

6. Fretham SJB, Carlson ES, Georgieff MK. The role of iron in learning and memory. Adv Nutr 2011;2:112-21.

7. Logan S, Martins S, Gilbert R. Iron therapy for improving psychomotor development and cognitive function in children under the age of three with iron deficiency anaemia. Cochrane Database Syst Rev 2001;(2):CD001444.

8. Nutrition for healthy term infants: recommendations from birth to six months: a joint statement of Health Canada, Canadian Paediatric Society, Dietitians of Canada, and Breastfeeding Committee for Canada. Ottawa (ON): Health Canada; updated 2012. Available: www.hc-sc.gc.ca/fn-an/nutrition/infant-nourisson/recom /index-eng.php (accessed 2013 Jan. 25).

9. Chalco JP, Huicho L, Alamo C, et al. Accuracy of clinical pallor in the diagnosis of anaemia in children: a meta-analysis. BMC Pediatr 2005;5:46-58.

10. Cogswell ME, Looker AC, Pfeiffer CM, et al. Assessment of iron deficiency in US preschool children and nonpregnant females of childbearing age: National Health and Nutrition Examination Survey 2003-2006. Am J Clin Nutr 2009;89:1334-42.

Affiliations: Department of Paediatrics and the Institute of Health Policy, Management and Evaluation, University of Toronto; The Hospital for Sick Children Research Institute; and Li Ka Shing Knowledge Institute of St. Michael's Hospital, Toronto, Ont.

Contributors: Both authors drafted and revised the article, and gave final approval of the version submitted for publication.

Decisions is a series that focuses on practical evidence-based approaches to common presentations in primary care. The articles address key decisions that a clinician may encounter during initial assessment. The information presented can usually be covered in a typical primary care appointment. Articles should be no longer than 650 words, may include one box, figure or table and should begin with a very brief description ( 75 words or less) of the clinical situation. The decisions addressed should be presented in the form of questions. A box providing helpful resources for the patient or physician is encouraged. 